\title{
A
}

Acta HealthMedica

Acta HealthMedica (ISSN: 2414-6528)

http://www.ActaHealthMedica.com

Volume: 1, Issue: 2, June 2016, Pages: 44-48, DOI: http://dx.doi.org/10.19082/ah44

\section{EVALUATION OF PELVIC ANGLES IN PATIENTS WITH ACUTE AND CHRONIC LOW BACK PAIN}

Seyyed Mohammad Jalil Abrisham ${ }^{1}$, Mohammad Reza Sobhan ${ }^{1}$, Amin Zare Banadkuki ${ }^{2}$

1: M.D., Assistant Professor, Department of Orthopedic Surgery, Shahid Sadoughi Hospital, Shahid Sadoughi University of Medical Sciences, Yazd, Iran

2: Medical Student, School of Medicine, Shahid Sadoughi University of Medical Sciences, Yazd, Iran

\section{TYPE OF ARTICLE: ORIGINAL}

\begin{abstract}
Introduction: Low back pain is a major health problem that mostly affects adults. Despite great efforts to identify the causes of this pain, they are still unknown. Several observations have been concerning the effect of multiple factors on low back pain. Postural changes are one of the main risk factors of low back pain. Many studies have emphasized the importance of sagittal spine-pelvic angle in maintaining proper and balanced posture in normal people. Hence, the present paper aims to study these changes.

Methods: A cross-sectional study was carried out on patients with acute and chronic low back pain referred to Baghaeipour Clinic of Shahid Sadoughi Hospital, Yazd, Iran, from February 2015 to April 2016. Anteriorposterior and lateral pelvic graphs were measured for patients. Patients with a history of surgery, spondylolisthesis, history of fracture in lumbar spine, and pathological fractures were excluded. Information obtained from patients and measurement of sacral inclination, pelvic tilt, and sacral angle was recorded in a predeveloped questionnaire. Pain intensity of patients also was measured and recorded using the Oswestry Disability Questionnaire. All data and information were statistically analyzed with the discriptional analysis in SPSS version 20.

Results: One hundred patients (54 male, 46 female) with a mean age of $48.45 \pm 14.61$ years were enrolled. The mean value of sacral inclination, pelvic tilt, and the sacral angle was obtained $7.92 \pm 31.84,6.79 \pm 22.19$, and $5.65 \pm 32.40$, respectively. In addition, the mean disability percentage of patients was $40.10 \pm 10.22$.

Conclusion: The study findings indicate changes in the posture of the spine and pelvis in patients with low back pain in both acute and chronic types. The changes that occurred in these patients may be associated with the job status, underlying diseases, and other effective factors. To identify these factors, more extensive studies with larger samples are required.

KEYWORDS: Low back pain, Pelvic angle, Acute low back pain, Chronic low back pain
\end{abstract}

\section{INTRODUCTION}

Low back pain is a major health problem that mostly affects adults (1). This disease is common and costly and affects more than $80 \%$ of the US population during their lifetime (2-3). According to the American Institute for Health Information (2002), low back pain is the most common form of pain in the United States, and $26.4 \%$ of those surveyed in the last three months had experienced low back pain once during their lifespan. The extensive effects of low back pain on the population involved with physical works have caused this disease to be the most important reason for seeking redress and the fourth factor of health costs in the United States. Despite the important role of swayback in low back pain, there are wide differences between people in this regard. Swayback is determined by radiological studies (4). Despite great efforts made to identify the cause of these pains, they are still unknown. In subsequent years, several theories, including weakness of the abdominal muscles, atrophic changes, and the supporting muscles of the spine were raised, but the stabilizing role of the spine muscles in causing low back pain was more emphasized, as the impact of the exercises strengthening the supporting muscles of the spine has been

\section{Correspondence:}

Amin Zare Banadkuki, Medical Student, School of Medicine, Shahid Sadoughi University of Medical Sciences, Yazd, Iran. Tel: +98.3536282066, Fax:+98.3536282066, E-mail: Aminzare69@gmail.com

Received: February 12, 2016, Accepted: June 18, 2016, Published: June 2016

iThenticate screening: February 14, 2016, English editing: June 23, 2016, Quality control: June 24, 2016

(C) 2016 The Authors. This is an open access article under the terms of the Creative Commons Attribution-NonCommercialNoDerivs License, which permits use and distribution in any medium, provided the original work is properly cited, the use is non-commercial and no modifications or adaptations are made. 
mentioned in some studies (5). There are several observations concerning the effects of multiple factors on low back pain (3). Aging, degeneration process, pregnancy, and lifestyle are the most important factors causing low back pain. A study has revealed that low back pain in patients is directly associated with a BMI (body mass index) below 25 $\mathrm{kg} / \mathrm{cm}^{2}$. Other studies have shown that some factors such as increased lumbar lordosis, weight gain, reduced movements of the spine, and BMI may be associated with low back pain (6). Postural changes are one of the main risk factors of low back pain (2). Poor posture is the cause of stretching in ligaments and muscles of the back, which indirectly alters the curvature of the lumbar spine (1). Several studies have been conducted for identifying the causes of common low back pain. One reason expressed in this field is anatomical changes in the posture of the spine to the pelvis. Hence, the present study aims to measure and investigate these changes and find their relationship with the severity of low back pain and the disability caused by it.

\section{MATERIAL AND METHODS}

\subsection{Research design and setting}

A cross-sectional study was carried out on patients with acute and chronic low back pain referred to Baghaeipour Clinic of Shahid Sadoughi Hospital, Yazd, Iran, between February 2015 and April 2016.

\subsection{Sampling}

The statistical population included all patients with low back pain referred to Baghaeipour Clinic of Shahid Sadoughi Hospital in Yazd, 100 of whom (48 patients with acute low back pain and 52 patients with chronic low back pain) were selected as the sample. Patients were selected using the simple census.

\subsection{Selection criteria}

All patients with low back pain that referred to Baghaeipour Clinic of Shahid Sadoughi Hospital in Yazd were included. Patients with a history of surgery, spondylolisthesis, history of fracture in lumbar spine, and pathological fracture were excluded.

\subsection{Data collection}

Information obtained from patients and measurement of sacral inclination, pelvic tilt, and the sacral angle was recorded in a predeveloped questionnaire. Pain intensity of patients also was measured and recorded using the Oswestry Disability Questionnaire. Anterior-posterior and lateral pelvic graphs were prepared for the patients, and then their information was recorded in a predeveloped questionnaire. Pain intensity also was measured and recorded using the Oswestry Disability Questionnaire. Pelvic angles were measured and recorded by an examiner using the anterior-posterior and lateral pelvic graphs (the questionnaires used in this study are presented in the appendices). Sacral inclination: the angle between the diagonal line from the posterior edge of the first sacral vertebra and the vertical line crossing it. Pelvic tilt: the angle of the spine line and the hip-binding line with the center of an upper plate of vertebrae S1. Sacral angle: the angle between the line of the upper edge of the first sacral vertebra and the horizontal line crossing it.

\subsection{Research ethics}

All patients were alerted about the study process, and if they wanted to leave the study, it was their choice. Informed consent was obtained from all patients before their inclusion in the study. We did not perform any additional invasive procedures on the patients to acquire additional data.

\subsection{Statistical analyses}

All data and information were statistically analysed with description analysis in IBM@ SPSSC Statistics version 20 (Armonk, NY, USA) software.

\section{RESULTS}

In this study, 100 patients participated that 48 of them had acute low back pain, and 52 of them suffered from chronic low back pain (Table 1-4). Patients were in the age range of 21-76 with a mean of 48.45 \pm 14.61 . Mean weight and height of patients were $7.86 \pm 74.48 \mathrm{~kg}$ and $7.43 \pm 173.46 \mathrm{~cm}$, respectively. BMI measurement also showed that mean BMI of patients is $2.37 \pm 24.77 \mathrm{~kg} / \mathrm{m}^{2}$. In addition, mean values of pelvic tilt, sacral angle, and sacral inclination were obtained $22.19 \pm 6.79,31.84 \pm 7.92$, and 5.65 \pm 32.40 , respectively. The Oswestry Disability Questionnaire used to measure disability percentage and mean disability percentage of patients in this study was equal to $40.10 \pm 10.22$. 
Table 1. Frequently distribution of age, weight, height, BMI, and disability in patients with acute low back pain

\begin{tabular}{|l|l|l|l|}
\hline Variables & Below 40 & 21 & 43.8 \\
\hline \multirow{3}{*}{ Age (year) } & $40-60$ & 19 & 39.6 \\
\cline { 2 - 4 } & Above 60 & 8 & 16.7 \\
\hline \multirow{3}{*}{ Gender } & Male & 28 & 58.3 \\
\cline { 2 - 4 } & Female & 20 & 41.7 \\
\hline \multirow{2}{*}{ Body Mass Index $\left(\mathrm{kg} / \mathrm{m}^{2}\right)$} & Below 25 & 25 & 52.1 \\
\cline { 2 - 4 } & Above 25 & 23 & 47.9 \\
\hline Disability (score) & Low (0-20) & 1 & 2.1 \\
\cline { 2 - 4 } & Moderate (21-40) & 25 & 53.2 \\
\cline { 2 - 4 } & Severe (41-60) & 21 & 44.7 \\
\hline
\end{tabular}

Table 2. Age, weight, height, BMI, and pelvic angles in patients with acute low back pain

\begin{tabular}{|l|l|l|l|}
\hline Variables & Mean \pm SD & Minimum & Maximum \\
\hline Age, year & $44.64 \pm 13.30$ & 21 & 70 \\
\hline Weight, kg & $74.52 \pm 8.63$ & 56 & 95 \\
\hline Height, cm & $173.58 \pm 8.03$ & 148 & 184 \\
\hline Body Mass Index, $\mathrm{kg} / \mathrm{m}^{2}$ & $24.73 \pm 2.39$ & 19.94 & 32.11 \\
\hline Pelvic tilt, cm & $20.79 \pm 6.30$ & 10 & 35 \\
\hline Sacral angle, degree & $32.0 \pm 8.72$ & 20 & 58 \\
\hline Sacral inclination, degree & $32.85 \pm 5.04$ & 18 & 44 \\
\hline Disability, score & $40.12 \pm 9.96$ & 20 & 68 \\
\hline
\end{tabular}

Table 3. Frequently distribution of age, weight, height, BMI, and disability in patients with chronic low back pain

\begin{tabular}{|l|l|l|l|}
\hline Variables & $\mathrm{n}$ & $\%$ \\
\hline Age (year) & Below 40 & 14 & 26.9 \\
\cline { 2 - 4 } & $40-60$ & 20 & 38.5 \\
\cline { 2 - 4 } & Above 60 & 18 & 34.6 \\
\hline \multirow{3}{*}{ Gender } & Male & 26 & 50 \\
\cline { 2 - 4 } & Female & 26 & 50 \\
\hline \multirow{2}{*}{ Body Mass Index $\left(\mathrm{kg} / \mathrm{m}^{2}\right)$} & Below 25 & 30 & 57.7 \\
\cline { 2 - 4 } & Above 25 & 22 & 42.3 \\
\hline Disability (score) & Low (0-20) & 0 & 0 \\
\cline { 2 - 5 } & Moderate (21-40) & 28 & 53.8 \\
\cline { 2 - 4 } & Severe (41-60) & 24 & 46.2 \\
\hline
\end{tabular}

Table 4. Age, weight, height, BMI, and pelvic angles in patients with chronic low back pain

\begin{tabular}{|l|l|l|l|}
\hline Variables & Mean \pm SD & Minimum & Maximum \\
\hline Age, year & $51.96 \pm 15.01$ & 21 & 76 \\
\hline Weight, $\mathrm{kg}$ & $74.44 \pm 7.16$ & 64 & 103 \\
\hline Height, cm & $173.34 \pm 6.91$ & 156 & 185 \\
\hline Body Mass Index, $\mathrm{kg} / \mathrm{m}^{2}$ & $2.39 \pm 24.81$ & 18.99 & 32.05 \\
\hline Pelvic tilt, cm & $23.48 \pm 7.02$ & 8 & 38 \\
\hline Sacral angle, degree & $31.69 \pm 7.18$ & 20 & 50 \\
\hline Sacral inclination, degree & $31.98 \pm 5.04$ & 20 & 53 \\
\hline Disability, score & $40.12 \pm 6.18$ & 24 & 60 \\
\hline
\end{tabular}

\section{DISCUSSION}

Diagnosis of patients with low back pain has always been a concern for doctors. There is a fundamental point that only $20 \%$ of people with low back pain show a pathoanatomic disorder, and most of them are known under the title of non-specific low back pain. This is not pleasant for doctors and patients. Therefore, diagnosis of patients with low back pain based on a pathoanatomic disorder is of special importance (23). Whereas postural changes are one of the main risk factors of low back pain, which cause pathoanatomic disorders, changing in sagittal spin-pelvis angle is 
one of the pathoanatomic disorders. By this study, different factors were obtained as the cause of low back pain, which, in other studies, had different results. In the present study, mean disability percentage of patients using the Oswestry Disability Questionnaire was obtained (40.10 \pm 10.22 ). In the study conducted by Brumagne et al. (6) on the relationship of paraspinal muscles with low back pain, disability percentage has been reported to be $7 \pm 6.8$. This difference can be attributed to the higher mean age of patients in the present study (48) than in the above-mentioned study (21). In the study conducted by Youdas et al., lumbar lordosis and chronic low back pain, disability percentage was obtained $21 \%$ (10), while the figure for patients with chronic low back pain was $41 \%$. This difference can be attributed to the smaller sample size and higher BMI in the study of Youdas et al. In another study carried out by Valayer on the status of pelvic angles in patients with chronic low back pain, mean angle of pelvic tilt was obtained $13.9^{\circ}(7)$, while this figure for patients with chronic low back pain in the present study was $23.48 \pm 7.02^{\circ}$. This is due to a lower number of patients in this study. In a study conducted by Barrey et al. in 2007 on sagittal changes in patients with degenerative disorders, mean angle of pelvic tilt was reported to be 19.9. This figure in the present study was obtained at $6.79 \pm 22.19^{\circ}$. This difference can be attributed to the affliction of patients with disc diseases in the study of Barrey et al. It has been reported by previous studies that pelvis angles, and especially pelvic tilt, increases in patients with chronic low back pain, while this was not observed in the present study. All these changes have a relation with a patient's job status, underlying diseases, and other effective factors, which, in other studies, have not been mentioned. The findings of this descriptive study indicate changes in acute and chronic types of low back pain. To study these changes, further extensive studies on larger samples and different population are required. Therefore, it is noted that further studies need to be developed and carried out by taking the points mentioned in order to identify these changes. In this study, we did not analyze the relation between data, which can be one of the deficiencies in this study.

\section{CONCLUSIONS}

The study findings indicate changes in the posture of the spine and pelvis in patients with low back pain in both acute and chronic types. The changes occurring in these patients may be associated with the job status, underlying diseases, and other effective factors. To identify these factors, more extensive studies with larger samples are required.

\section{ACKNOWLEDGMENTS:}

This paper was extracted from the correspondence author's thesis; there was no grant for this study. The authors thank the staff in the Orthopaedic Department of Shahid Sadoughi hospital, Yazd, Iran, for their assistance in data collection. No funding was taken for this study.

\section{CONFLICT OF INTEREST:}

There is no conflict of interest to be declared.

\section{AUTHORS' CONTRIBUTIONS:}

All authors contributed to this project and article equally. All authors read and approved the final manuscript.

\section{REFERENCES:}

1) Evcik D, Yücel A. Lumbar lordosis in acute and chronic low back pain patients. Rheumatology international. 2003; 23(4): 163-5. doi: 10.1007/s00296-002-0268-x. PMid: 12856140.

2) O'Sullivan K, Verschueren S, Van Hoof W, Ertanir F, Martens L, Dankaerts W. Lumbar repositioning error in sitting: Healthy controls versus people with sitting-related non-specific chronic low back pain (flexion pattern). Manual therapy. 2013; 18(6): 526-32. doi: 10.1016/j.math.2013.05.005. PMid: 23756034.

3) Seay JF, Van Emmerik RE, Hamill J. Low back pain status affects pelvis-trunk coordination and variability during walking and running. Clinical Biomechanics. 2011; 26(6): 572-8. doi: 10.1016/j.clinbiomech.2010.11.012. PMid: 21536356.

4) De Carvalho DE, Soave D, Ross K, Callaghan JP. Lumbar spine and pelvic posture between standing and sitting: a radiologic investigation including reliability and repeatability of the lumbar lordosis measure. Journal of manipulative and physiological therapeutics. 2010; 33(1): 48-55. doi: 10.1016/j.jmpt.2009.11.008. PMid: 20114100

5) Ferreira PH, Ferreira ML, Maher CG, Herbert RD, Refshauge K. Specific stabilisation exercise for spinal and pelvic pain: a systematic review. Australian Journal of Physiotherapy. 2006; 52(2): 79-88. doi: 10.1016/S0004-9514(06)70043-5. 
6) Ghiasi F, St K, Hoseinifar M, Akbari A. The relationship between lumbar and thoracic curves with body mass index and low back pain in students of Zahedan University of Medical Sciences. J Med Sci. 2007; 7(6): 984-90. doi: 10.3923/jms.2007.984.990.

7) Gilliam J, Brunt D, MacMillan M, Kinard RE, Montgomery WJ. Relationship of the pelvic angle to the sacral angle: measurement of clinical reliability and validity. Journal of Orthopaedic \& Sports Physical Therapy. 1994; 20(4): 193-9. doi: 10.2519/jospt.1994.20.4.193. PMid: 7987379.

8) Cibulka MT, Delitto A, Koldehoff RM. Changes in Innominate Tilt After Manipulation of the Sacroiliac Joint in Patients with Low Back Pain An Experimental Study. Physical Therapy. 1988; 68(9): $1359-63$. PMid: 2971233.

9) Lee JH, Yoo WG. Application of posterior pelvic tilt taping for the treatment of chronic low back pain with sacroiliac joint dysfunction and increased sacral horizontal angle. Physical Therapy in Sport. 2012; 13(4): 279-85. doi: 10.1016/j.ptsp.2011.10.003. PMid: 23068906.

10) May S, Littlewood C, Bishop A. Reliability of procedures used in the physical examination of non-specific low back pain: a systematic review. Australian journal of physiotherapy. 2006; 52(2): 91-102. doi: 10.1016/S0004-9514(06)70044-7.

11) Haddas R, James CR, Hooper TL. Lower extremity fatigue, sex, and landing performance in a population with recurrent low back pain. Journal of athletic training. 2015; 50(4): 378-84. doi: 10.4085/1062-605049.3.61. PMid: 25322344. PMCid: PMC4560000.

12) Penney T, Ploughman M, Austin MW, Behm DG, Byrne JM. Determining the Activation of Gluteus Medius and the Validity of the Single Leg Stance Test in Chronic, Nonspecific Low Back Pain. Archives of physical medicine and rehabilitation. 2014; 95(10): 1969-76. doi: 10.1016/j.apmr.2014.06.009. PMid: 24992020.

13) Brumagne S, Cordo P, Lysens R, Verschueren S, Swinnen S. The role of paraspinal muscle spindles in lumbosacral position sense in individuals with and without low back pain. Spine. 2000; 25(8): 989-94. doi: 10.1097/00007632-200004150-00015. PMid: 10767813.

14) Youdas JW, Garrett TR, Egan KS, Therneau TM. Lumbar lordosis and pelvic inclination in adults with chronic low back pain. Physical Therapy. 2000; 80(3): 261-75. PMid: 10696153.

15) Sakellaridis N. The influence of diabetes mellitus on lumbar intervertebral disk herniation. Surgical neurology. 2006; 66(2): 152-4. doi: 10.1016/j.surneu.2006.01.019. PMid: 16876608.

16) Chou R, Huffman LH. Nonpharmacologic therapies for acute and chronic low back pain: a review of the evidence for an American Pain Society/American College of Physicians clinical practice guideline. Annals of internal medicine. 2007; 147(7): 492-504. doi: 10.7326/0003-4819-147-7-200710020-00008. PMid: 17909210 .

17) Chaléat-Valayer E, Mac-Thiong JM, Paquet J, Berthonnaud E, Siani F, Roussouly P. Sagittal spino-pelvic alignment in chronic low back pain. European spine journal. 2011; 20(5): 634-40. doi: 10.1007/s00586011-1931-2. PMid: 21870097. PMCid: PMC3175927.

18) Lazennec JY, Ramare S, Arafati N, Laudet CG, Gorin M, Roger B, Hansen S, Saillant G, Maurs L, Trabelsi R. Sagittal alignment in lumbosacral fusion: relations between radiological parameters and pain. European Spine Journal. 2000; 9(1): 47-55. doi: 10.1007/s005860050008. PMid: 10766077. PMCid: PMC3611353.

19) Chanplakorn P, Sa-ngasoongsong $P$, Wongsak S, Woratanarat $P$, Wajanavisit W, Laohacharoensombat W. The correlation between the sagittal lumbopelvic alignments in standing position and the risk factors influencing low back pain. Orthopedic reviews. 2012; 4(1): e11. doi: 10.4081/or.2012.e11.

20) Korovessis P, Stamatakis M, Baikousis A. Segmental roentgenographic analysis of vertebral inclination on sagittal plane in asymptomatic versus chronic low back pain patients. Journal of Spinal Disorders \& Techniques. 1999; 12(2): 131-7. doi: 10.1097/00002517-199904000-00009.

21) Tüzün C, Yorulmaz I, Cindaş A, Vatan S. Low back pain and posture. Clinical rheumatology. 1999; 18(4): 308-12. doi: 10.1007/s100670050107. PMid: 10468171.

22) Fairbank JC, Pynsent PB. The Oswestry Disability Index. Spine. 2000; 25(22): 2940-52. doi: 10.1097/00007632-200011150-00017.

23) Albert HB, Manniche C. Modic changes following lumbar disc herniation. European spine journal. 2007; 16(7): 977-82. doi: 10.1007/s00586-007-0336-8. PMid: 17334791. PMCid: PMC2219661.

24) Barrey C, Jund J, Noseda O, Roussouly P. Sagittal balance of the pelvis-spine complex and lumbar degenerative diseases. A comparative study about 85 cases. European Spine Journal. 2007 Sep 1;16(9):1459-67. doi: 10.1007/s00586-006-0294-6. PMid: 17211522. PMCid: PMC2200735. 